\title{
Retrato em família: imagens de cotidiano na beira do Tapajós
}

\author{
Chantal Medaets \& Lucie Robieux
}

História, trabalho, arranjos familiares, relações de poder, de amor, "de família". São alguns temas que evocam as imagens que aqui propomos das comunidades ribeirinhas de Pinhel e Parauá, na regiāo do baixo-Tapajós, estado do Pará. Pelo "fio" família são alguns aspectos não lineares da vida nessas comunidades que escolhemos aqui dar à ver. Como num caleidoscópio, trata-se de imagens recortadas que refletem um todo. $\mathrm{O}$ mesmo todo poderia ser totalmente outro virando apenas o corpo e mudando assim, por pouco que seja, o ângulo que capta a lente. Outras imagens se veria, outros temas trariam, mas falaríamos ainda da mesma realidade. $\mathrm{O}$ ângulo familia nos pareceu possibilitar reflexos interessantes, embora por certo não exaustivos, do cenário em questão.

Nele, este cenário camponês, amazônico, de história movimentada, o rio teve e tem presença marcante. Serviu, por exemplo, de "estrada" para a vinda, entre tantas outras, da família de Heitor, que deixou o Paraná expulsa pelo alagamento de suas terras pela hidrelétrica Itaipu, " $a$ gente morava lá onde hoje é embaixo d'água...". Nele também, vive a família de D. Darcy e Seu Estevão que reivindica hoje a identidade Maytapu, "povo que vivia aqui desde antes dessa guerra com os portugueses", explica Margareth, liderança jovem, católica e indígena que participa da criação da associação local de luta pelo reconhecimento étnico. Essa luta, no entanto, não é de todo consenso e traz divergências (é o mínimo que se pode dizer...) às vezes dentro da mesma família. Como conta Reginaldo, minutos antes da foto à mesa : "meu irmáo, foi por pouco que náo corta o cunhado de facão, por causa dessa história de ter que ser indio".

Compóem também o nosso ensaio-caleidoscópio imagens que dizem da intensa circulação infantil em família (e também fora dela...), da fundamental participação das crianças no trabalho cotidiano, da importância da relação entre pares, do papel e poder dos avós, da relação entre pai e filho, da presença tão marcante - e constante! - de um riso solto e sarrista...

São imagens que, no nosso entender, puxam histórias. Os ribeirinhos desta região costumam dizer que "tem coisa que é historia $e$ outras que não, que é fato 'acontecido mesmo". Que essas imagens possam puxar conversas de ambas, suscitando encontros de imaginário e materialidade, de invenção e fato, de rio e identidade. Esse foi o nosso intento.

autoras Chantal Medaets

Doutoranda do Centre D'Anthropologie Social - Canthel/Université Paris V - SHS

Sorbonne

Lucie Robieux

Mestre em economia/HEC-Paris

Recebido em 26/05/2011

Aceito para publicação em 24/08/2011 
I 84 | Chantal Medaets \& Lucie Robieux

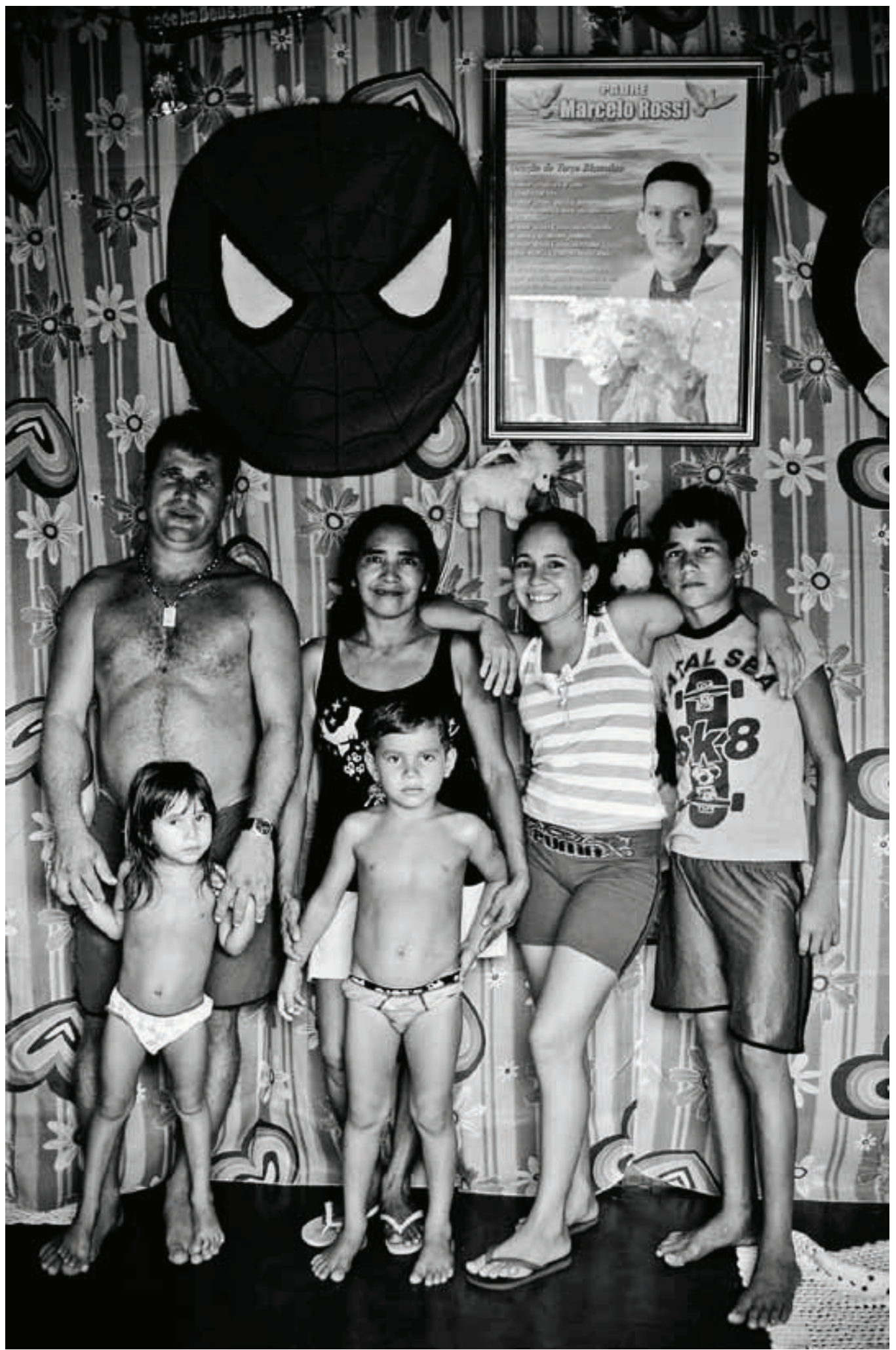

1. "Foi meus pais que vieram"

cadernos de campo, São Paulo, n. 20, p. 183-188, 2011 


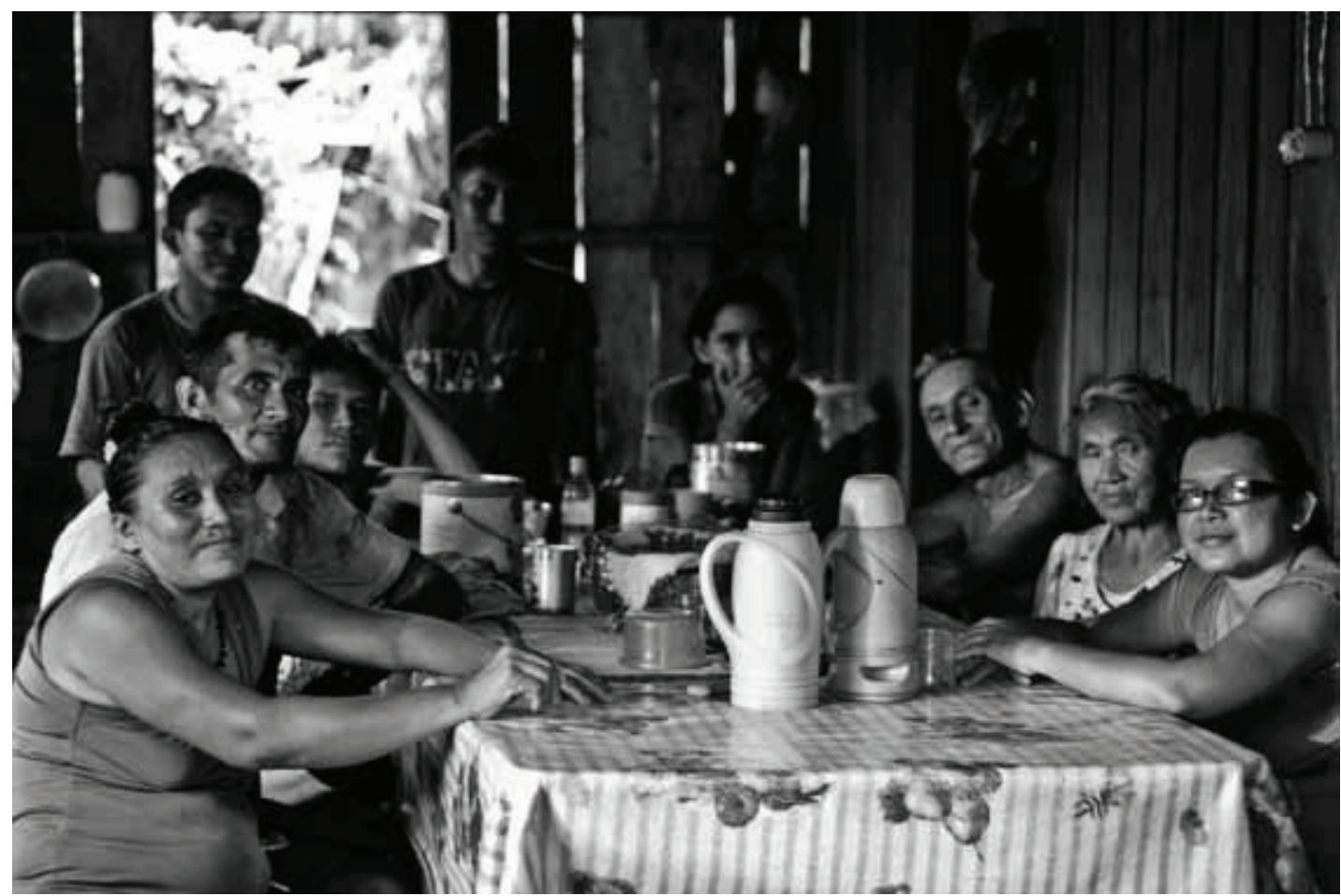

2. À mesa

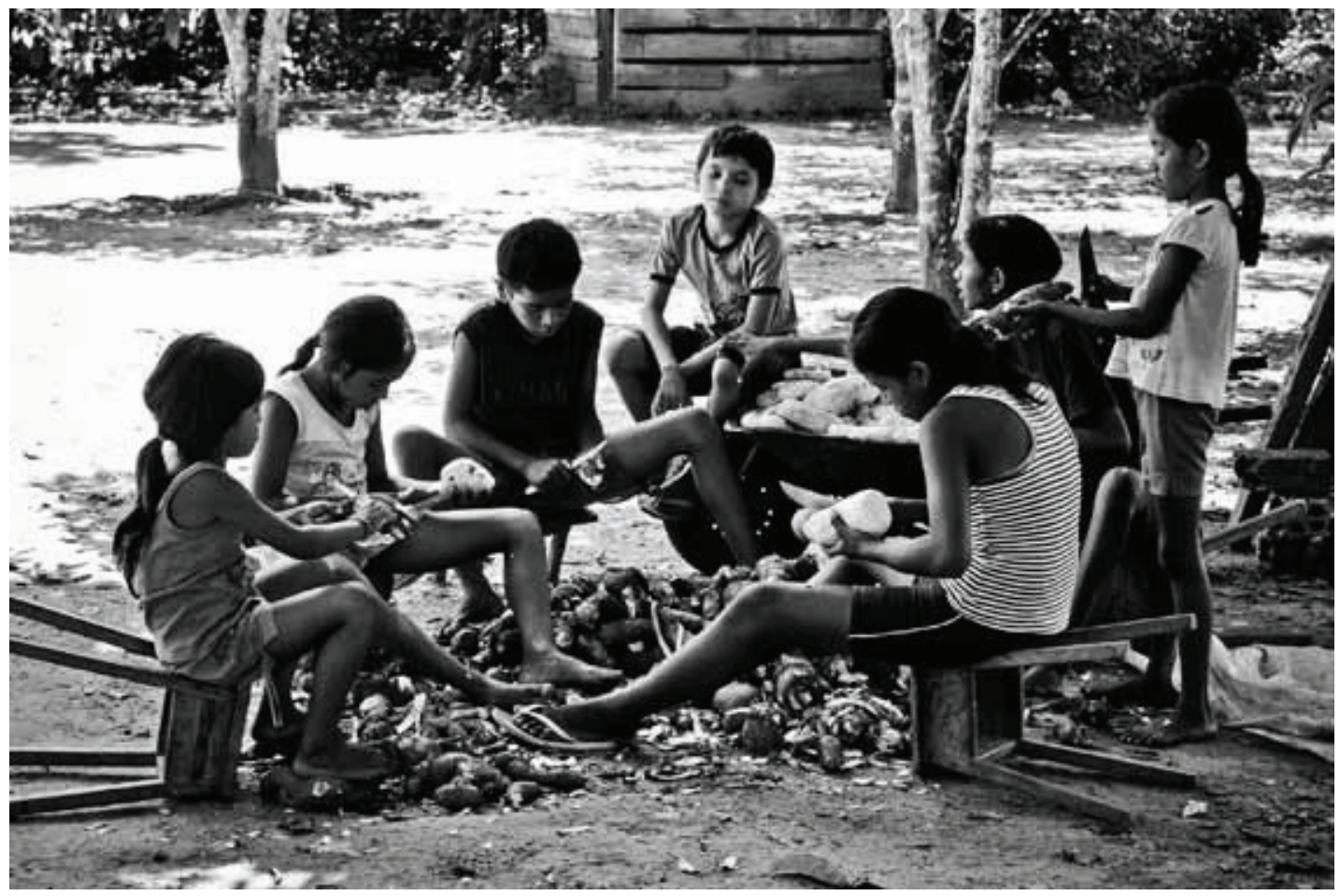

3. Trabalho em família 
i 86 | Chantal Medaets \& Lucie Robieux

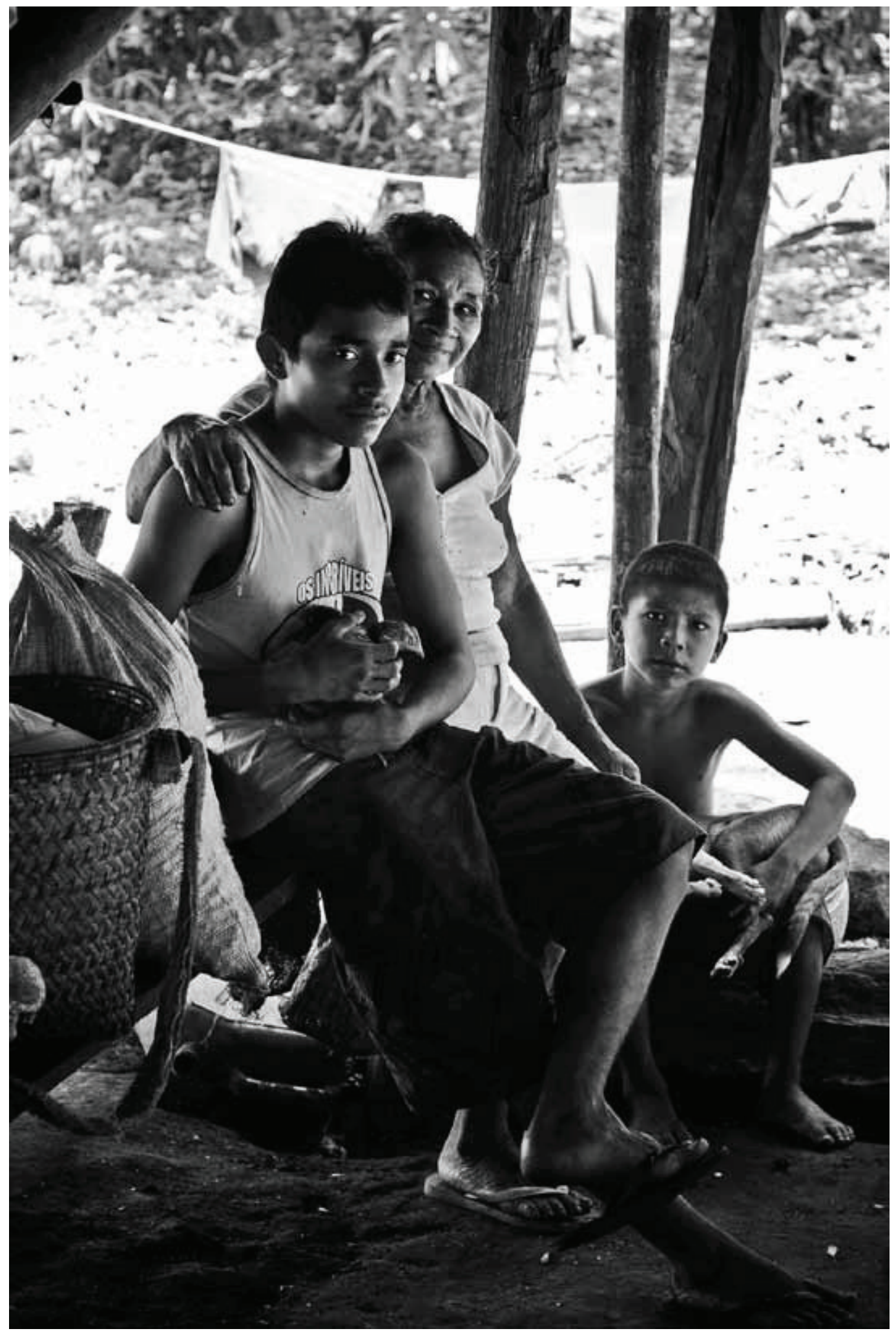

4. Netos"criado de filho"

cadernos de campo, São Paulo, n. 20, p. 183-188, 2011 


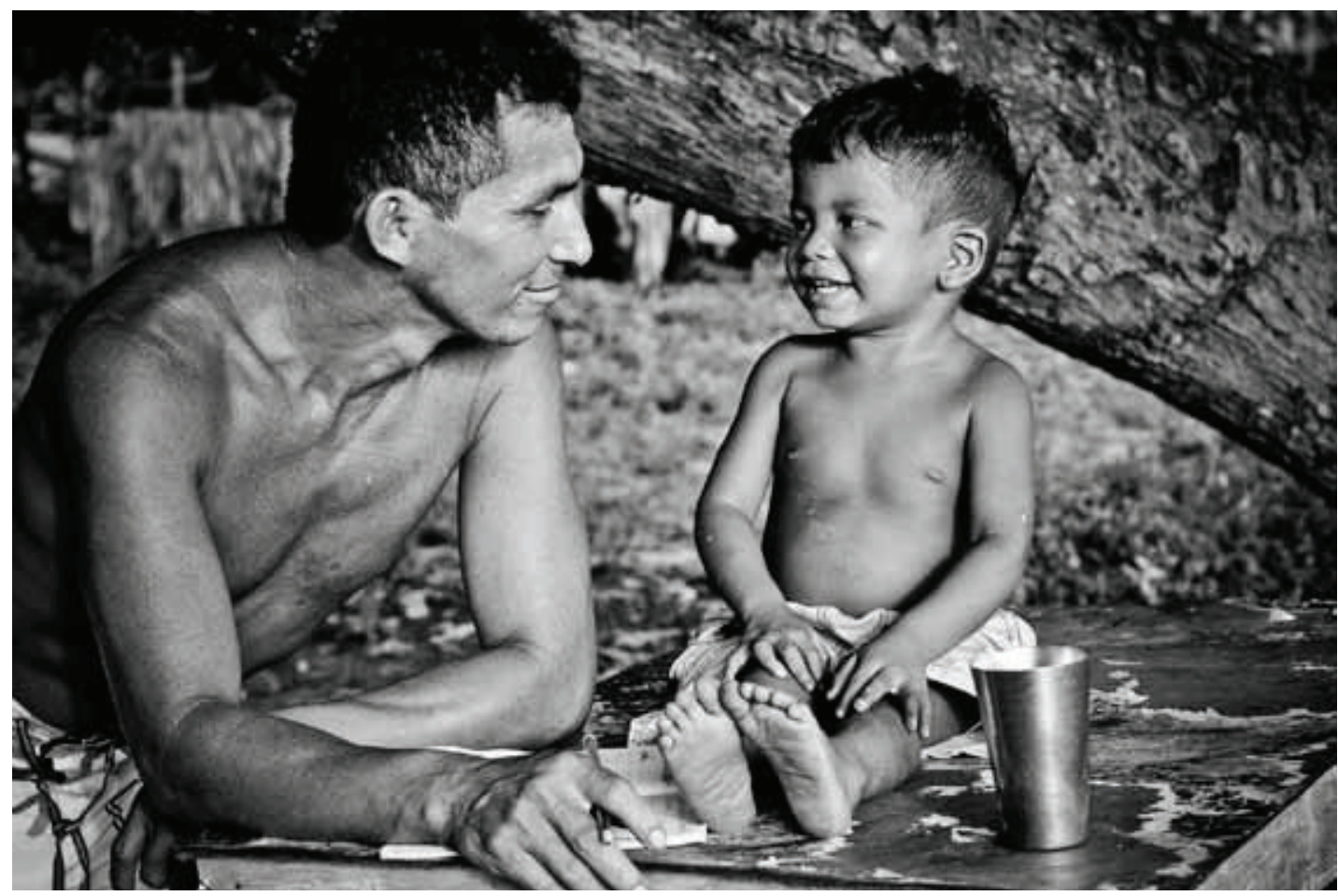

5. Tiago e Kennedy

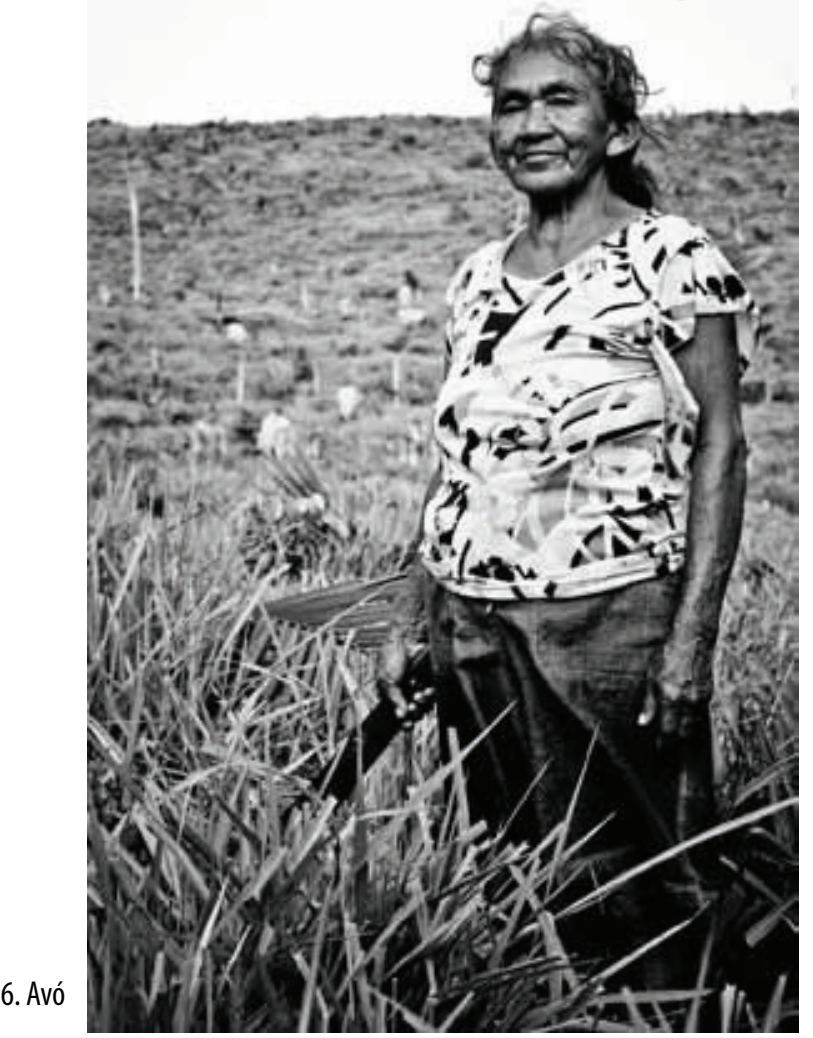


i 88 | Chantal Medaets \& Lucie Robieux

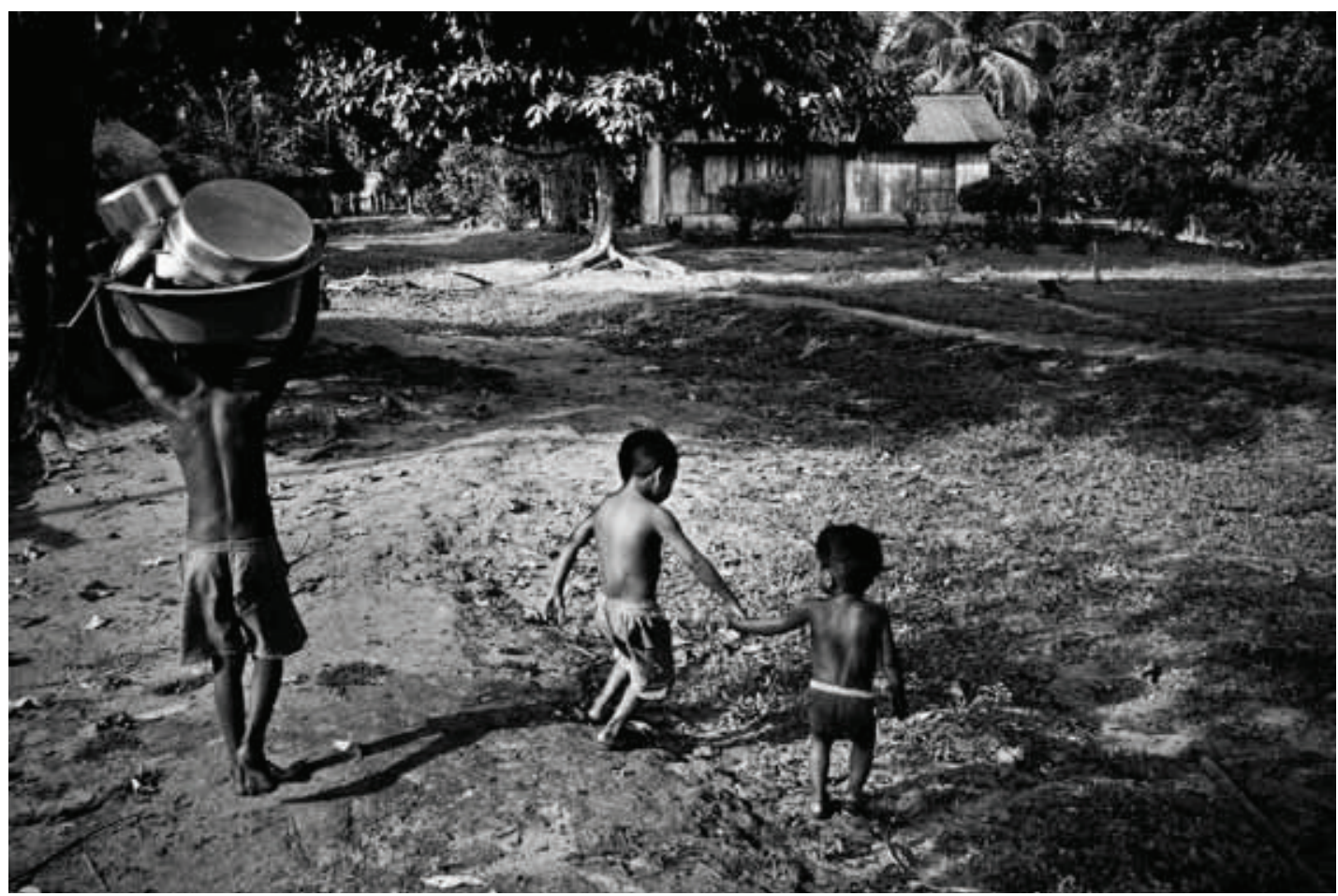

7. No caminho do igarapé

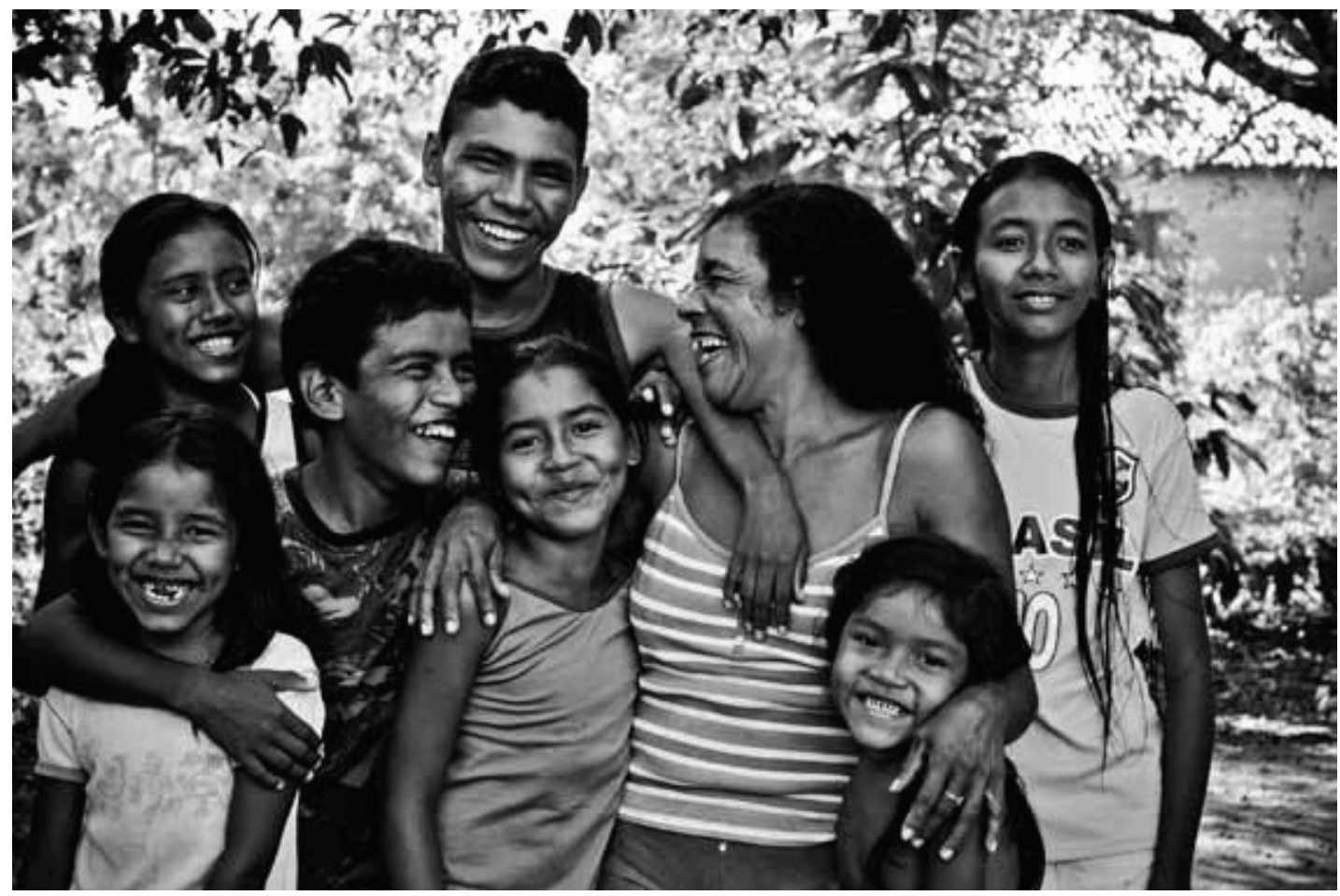

